\title{
Effect of Grain Size on the Fatigue Crack Growth in Steels at Temperatures 295 and $77 \mathrm{~K}$
}

\author{
Gejza ROSENBERG \\ Ph.D., Faculty of Metallurgy, Technical University of Kosice, Letná 9, 04200 Kosice, Slovakia. \\ E-mail: Gejza.Rosenberg@tuke.sk
}

(Received on January 23, 2003; accepted in final form on April 19, 2003)

\begin{abstract}
Fatigue crack growth (FCG) and threshold stress intensity in low carbon and HSLA steels with remarkably different ferrite grain sizes $\left(d_{f}\right)$ at room temperature and temperature of liquid nitrogen were investigated. The FCG rates were found to decrease with decreasing temperature for all investigated microstructural states and the influence of temperature decrease was the most significant in coarse grain microstructures. The threshold values of the stress intensity factor, $\left(\Delta K_{\mathrm{th}}\right)$, below which cracks do not propagate, decreased by between $29.1 \%\left(d_{\mathrm{f}}=2.7 \mu \mathrm{m}\right)$ and $49.3 \%\left(d_{\mathrm{f}}=88.4 \mu \mathrm{m}\right)$ when specimens were tested at the cryogenic temperature.

A general relationship between the FCG rate, the effects of grain boundary blocking on the plastic zone size and/or the crack-tip opening displacement and the effect of changing temperature, is discussed. Furthermore, the concept of a functional relation between tensile and fatigue data at cryogenic temperatures was also investigated. It was shown that the ratio of $\Delta K_{\text {th }}$ at $77 \mathrm{~K}$ to $\Delta K_{\text {th }}$ at $295 \mathrm{~K}$ is proportional to the second root of the ratio of the tensile strength values at these temperatures i.e. $\Delta K_{\text {th } 77 \mathrm{~K}} / \Delta K_{\text {th } 295 \mathrm{~K}} \approx$ $\left(\sigma_{\mathrm{u} 77 \mathrm{~K}} / \sigma_{\mathrm{u} 295 \mathrm{~K}}\right)^{1 / 2}$.

KEY WORDS: steel; cryogenic; grain size; fatigue crack growth; threshold; crack-tip opening displacement; plastic zone.
\end{abstract}

\section{Introduction}

Practically all structural components have natural inhomogeneities or holes, joints and other initial defects which reduce the crack initiation process and consequently, the fatigue life of structures depends primarily on the stage of the fatigue crack growth (FCG). ${ }^{1)}$ The resistance to crack growth is affected by many variables among which the role of microstructure in influencing the FCG behavior in various materials has been a subject of considerable research interest since many years.

In many papers the effect of grain size on the threshold condition for FCG is frequently discussed both theoretically and experimentally. In these works it is concluded that the primary requirement of fatigue crack growth is crack-tip dislocations emission and/or the above critical cyclic plastic zone size (CPZ). ${ }^{2,3)}$ Also it is supposed that the effect of slip band blocking by grain boundaries increased markedly when CPZ size tends to be equal to $\mathrm{df}$ and the threshold conditions for the FCG can be based on a critical crack-tip opening displacement (CTOD) criterion. ${ }^{4)}$

It would be therefore expected that as the test temperature will decrease and proportionally the yield strength $\left(\sigma_{\mathrm{y}}\right)$ increase the threshold values $\Delta K_{\text {th }}$ also decrease, because both the CPZ and the CTOD depend on $\sigma_{\mathrm{y}}$. This type of behavior has been observed by many researchers in various materials and generally the temperature decrease has a beneficial effect on the resistance to the FCG. ${ }^{5-14)}$
However, the experimentally measured data in the cited works show a significantly different temperature effect on the crack growth rates. The investigators of the influence of temperature decrease from room temperature to cryogenic temperatures revealed both little significant influence ${ }^{5,11,12)}$ and 80 -fold decrease of the FCG in steels and other materials also. ${ }^{6,7,13)}$ The problem of the microstructural influence at cryogenic temperatures on FCG behaviour is equally unsolved. ${ }^{14)}$

The aim of the present paper is to determine the FCG at $295 \mathrm{~K}$ and $77 \mathrm{~K}$ in steels with remarkable differences in grain size and, if possible, to show a functional relation between cryogenic fatigue and tensile properties.

\section{Experimental Details}

\subsection{Material and Specimens}

Experiments were conducted on the same materials, which were used in the previous study, ${ }^{15}$ ) where fatigue strength in smooth and notched specimens, and the growth of so-called short fatigue cracks were investigated. In this work are minutely presented only the results conducted on a commercially produced low-carbon steel (marked steel 1) and two HSLA steels (steel 2 and 3). The steels marked 1a and $1 \mathrm{~b}$ exhibited coarse-grain microstructures produced by heat treating of steel 1 .

Single edge notch, three point bend specimens machined perpendicularly and parallelly to the rolling direction had a 
Table 1. Tensile properties, ferrite grain size and threshold stress intensity factor ranges.

\begin{tabular}{llllllll}
\hline Steels & $\begin{array}{l}\mathrm{d}_{\mathrm{f}} \\
(\mu \mathrm{m})\end{array}$ & $\begin{array}{l}\mathrm{T} \\
(\mathrm{K})\end{array}$ & $\begin{array}{l}\sigma_{\mathrm{y}} \\
(\mathrm{MPa})\end{array}$ & $\begin{array}{l}\sigma_{\mathrm{u}} \\
(\mathrm{MPa})\end{array}$ & $\begin{array}{l}\sigma_{\text {th-1 }} \\
(\mathrm{MPa})\end{array}$ & $\begin{array}{l}\Delta \mathrm{K}_{\text {thp }} \\
\left(\mathrm{MPam}^{1 / 2}\right)\end{array}$ & $\begin{array}{l}\Delta \mathrm{K}_{\text {th }} \\
\left(\mathrm{MPam}^{1 / 2}\right)\end{array}$ \\
\hline $1 \mathrm{a}$ & 88.4 & 295 & 167 & 342 & 172 & 5.6 & 7.0 \\
& & 77 & 671 & 671 & - & - & 9.6 \\
$1 \mathrm{~b}$ & 63.4 & 295 & 186 & 357 & 180 & 5.6 & 6.3 \\
& & 77 & 693 & 704 & - & - & 8.5 \\
1. & 14.8 & 295 & 268 & 416 & 215 & 5.6 & 5.8 \\
& & 77 & 822 & 837 & - & - & 7.6 \\
2 & 6.3 & 295 & 461 & 574 & 338 & 5.9 & 5.8 \\
& & 77 & 932 & 948 & - & - & 7.5 \\
3 & 2.7 & 295 & 888 & 967 & 572 & 5.5 & 5.6 \\
& & 77 & 1259 & 1307 & - & - & 6,8 \\
\hline
\end{tabular}

thickness of 9 to $9.6 \mathrm{~mm}$, width $W=20 \mathrm{~mm}$ and working length $L=4 W$. The notches were prepared by electro-spark erosion with the depth an $=5.0 \mathrm{~mm}$ and radii $\rho=50 \mu \mathrm{m}$. The surface of all specimens was subjected to metallographic polishing. Fatigue tests were performed at the frequency, $f=25 \mathrm{~Hz}$ and stress ratio $R=0.03$ at temperatures ranging from room to liquid nitrogen temperature (in this work only results for two temperatures namely $295 \mathrm{~K}$ and $77 \mathrm{~K})$.

\subsection{Experimental Procedures}

All specimens were precracked over a length of $\approx 0.7$ $\mathrm{mm}$. After crack initiation in the samples at the level of $\Delta K=6$ to $7 \mathrm{MPa} \mathrm{m}^{1 / 2}$ the loading was gradually decreased or maintained at a constant level of $\Delta K$ with the aim to determine the threshold value of stress intensity factor range $\left(\Delta K_{\mathrm{th}}\right)$, defined by the decrease of the FCG below the level of $d a / d N=2 \times 10^{-7} \mathrm{~mm} /$ cycle. Subsequently, these precracked specimens were annealed in vacuum to remove residual stresses. For both temperatures tested minimally three specimens were used for each structural state and direction. Only the FCG data measured at increasing value of $\Delta K$ were recorded. The crack length was monitored using an optical microscope and potential drop technique. During the cryogenic tests the liquid nitrogen level was carefully maintained slightly below the growing crack tip in order to eliminate its direct contact with the fracture surface. The loading level was increased in such a way that each additional increase in the $\Delta K$ value occurred only after the FCG for the length corresponding to minimally three-fold of the PZ size. Fracture surfaces were examined by scanning electron microscope.

\section{Results}

\subsection{Fatigue Crack Growth Rate}

The average size of grains $\left(d_{\mathrm{f}}\right)$, yield stress $\left(\sigma_{\mathrm{y}}\right)$ ultimate strength $\left(\sigma_{\mathrm{u}}\right)$ and fatigue limit $\left(\sigma_{0}\right)$ for smooth specimens subjected to bending stress at stress ratio $R=-1$, at temperature of $295 \mathrm{~K}$ as well as of $77 \mathrm{~K}$ are summarized in Table 1.

In Table 1 are presented the threshold values of stress intensity of FCG for the two test temperatures $\left(\Delta K_{\text {th } 295}\right.$ and $\left.\Delta K_{\text {th } 77}\right)$ and also the threshold values for fatigue crack initiation leading to failure of the sample with a notch radius of $\rho=50 \mu \mathrm{m}\left(\Delta K_{\text {th }}\right)$ measured in a former work. ${ }^{15)}$ In this works it was demonstrated that on the specimens with a sharp notch as well as in the specimens with electro-spark removal of fracture surface behind long-crack tip, the FCG

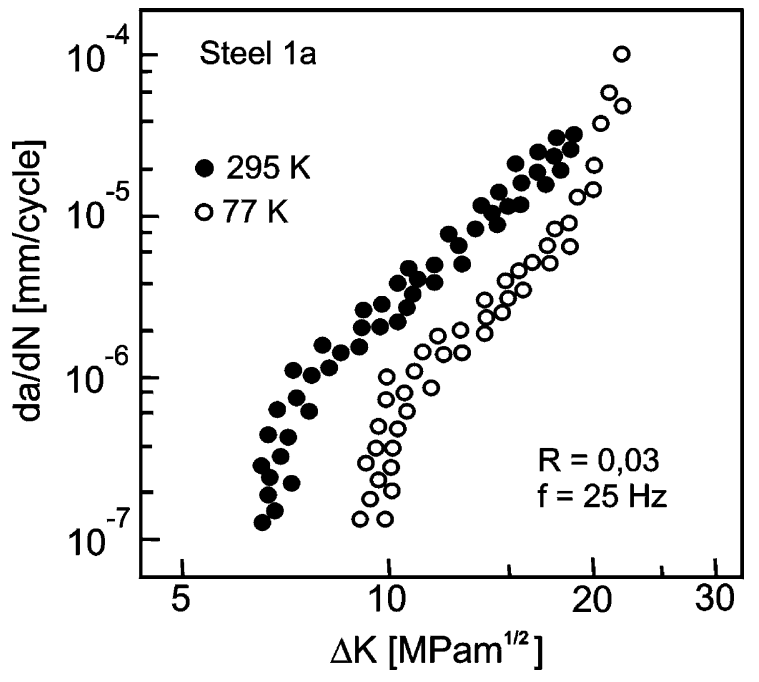

Fig. 1. Variations in fatigue crack growth rates with stress intensity factor range $(\Delta K)$ for steel 1a with grain size $d_{\mathrm{f}}=88.4 \mu \mathrm{m}$ at temperatures of 295 and $77 \mathrm{~K}$.

occurred below the level of the $\Delta K_{\mathrm{th}}$, which was determined by load shedding technique. This supposedly illogical result that samples with crack exhibit better fatigue resistance than the notched were explicated as in Ref. 3) by the different levels of stress intensity at crack tip closing i.e. by the concept of effective stress intensity range $\Delta K_{\text {eff }}$. Similar findings were obtained for the Ti-6Al-2.5Mo-1.5Cr alloy in various structural states. ${ }^{16)}$

The rates of FCG at room temperature and the temperature of liquid nitrogen (points with open marks) for all five steels/heat treatment conditions are presented in the form of $d a / d N-\Delta K$ graph in Figs. 1 to $\mathbf{5}$. Similarly to the tensile and fatigue tests on smooth and notched specimens ${ }^{15)}$ also the FCG results at both temperatures ware essentially independent of the orientation of specimens to the rolling direction. Therefore the FCG rates measured for both $\mathrm{T}-\mathrm{L}$ and $\mathrm{L}-\mathrm{T}$ directions are plotted together. The data for all steels are situated at both temperatures within a single band and it is clear that decreasing the temperature increased the resistance to crack growth except for the rates above $d a / d N \approx 2 \times$ $10^{-5} \mathrm{~mm} /$ cycle.

It is known from a number of studies (for example, Refs. 2)-4)) that the grain size effect is the most important in the near-threshold region, however, at high value of $K$ (where closure effects are negligible) its effect disappears. In contrast, the data in Figs. 1 to 5 are influenced by microstructure over the entire range of growth rates. The experimental results on Fig. 1 to 5 show that the form of the $d a / d N-\Delta K$ 


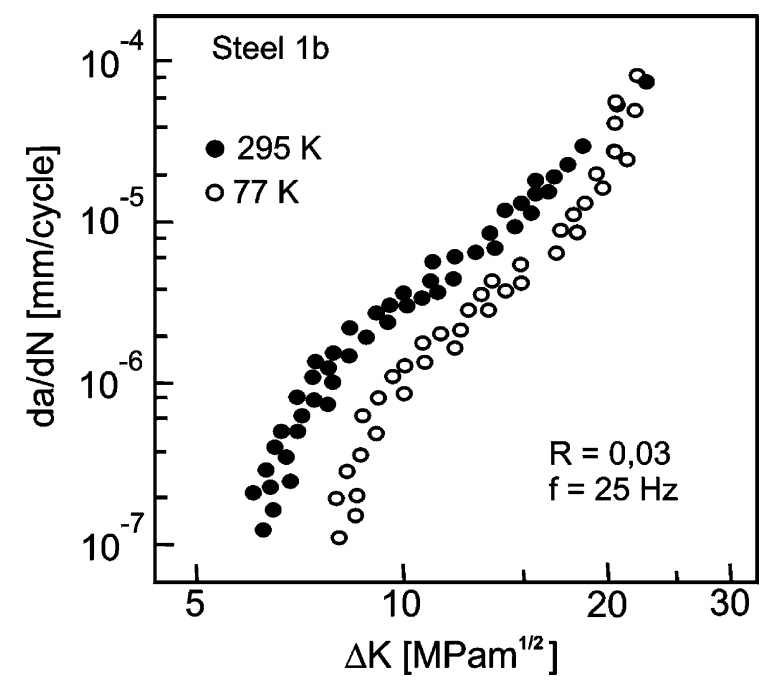

Fig. 2. Variations in fatigue crack growth rates with stress intensity range $(\Delta K)$ for steel $1 \mathrm{~b}$ with grain size $d_{\mathrm{f}}=63.4 \mu \mathrm{m}$ at temperatures of 295 and $77 \mathrm{~K}$.

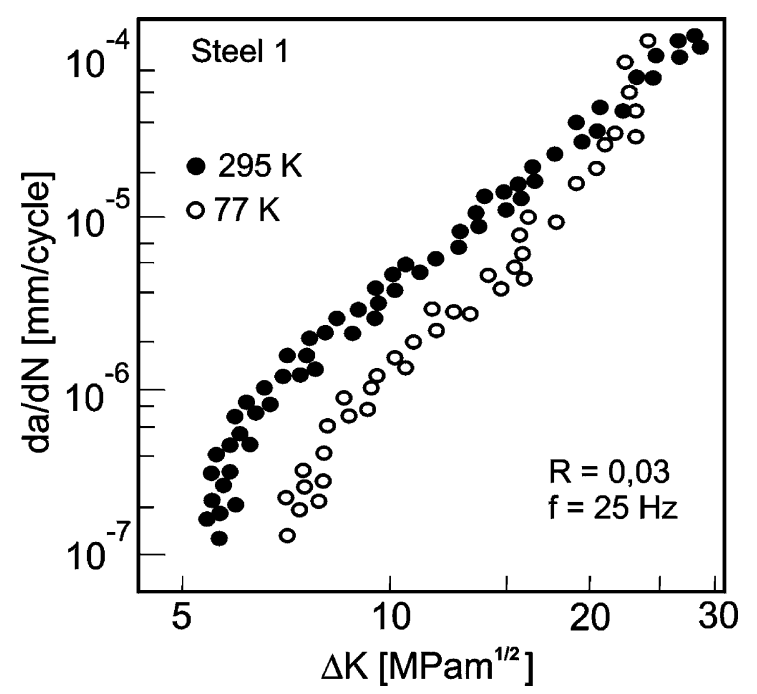

Fig. 3. Variations in fatigue crack growth rates with stress intensity range $(\Delta K)$ for steel 1 with grain size $d_{\mathrm{f}}=14.8 \mu \mathrm{m}$ at temperatures of 295 and $77 \mathrm{~K}$.

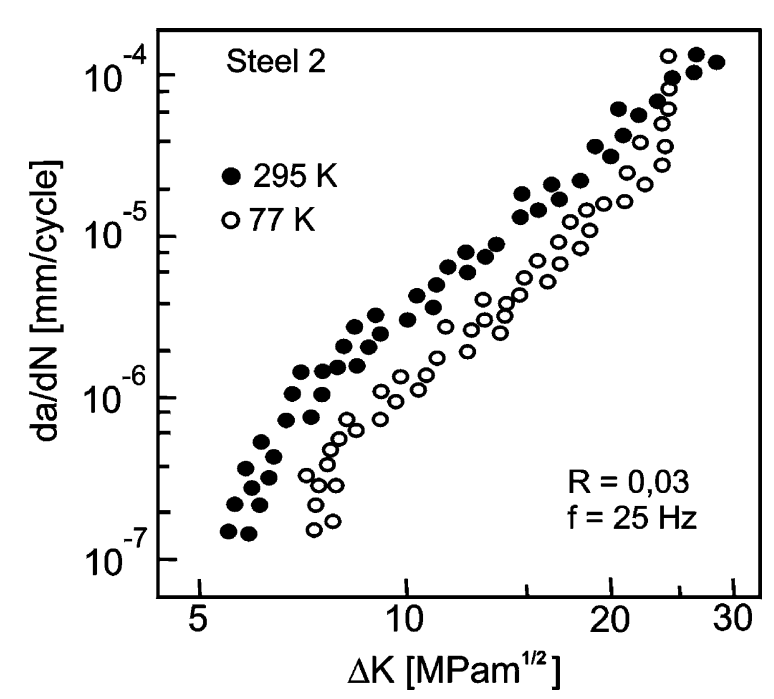

Fig. 4. Variations in fatigue crack growth rates with stress intensity range $(\Delta K)$ for steel 2 with grain size $d_{\mathrm{f}}=6.3 \mu \mathrm{m}$ at temperatures of 295 and $77 \mathrm{~K}$.

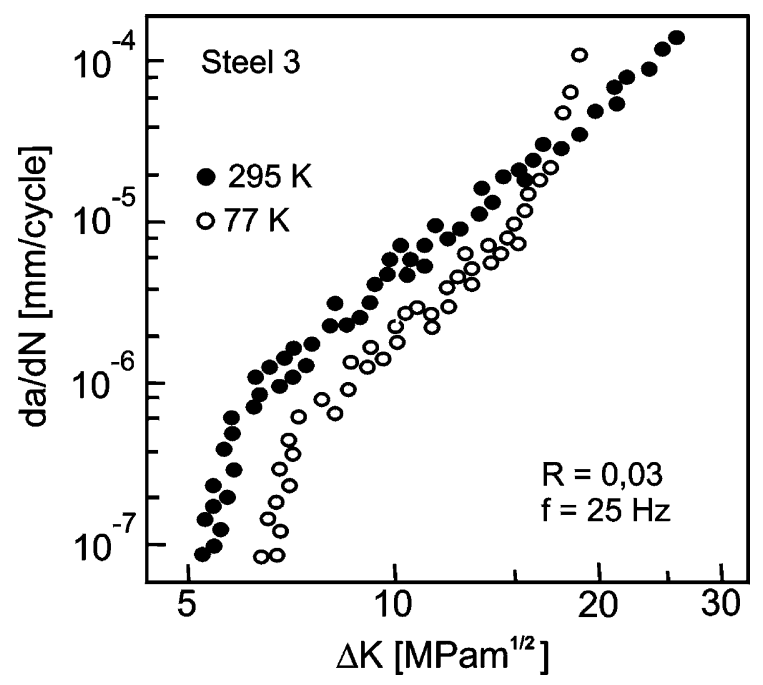

Fig. 5. Variations in fatigue crack growth rates with stress intensity range $(\Delta K)$ for steel 3 with grain size $d_{\mathrm{f}}=2.7 \mu \mathrm{m}$ at temperatures of 295 and $77 \mathrm{~K}$.

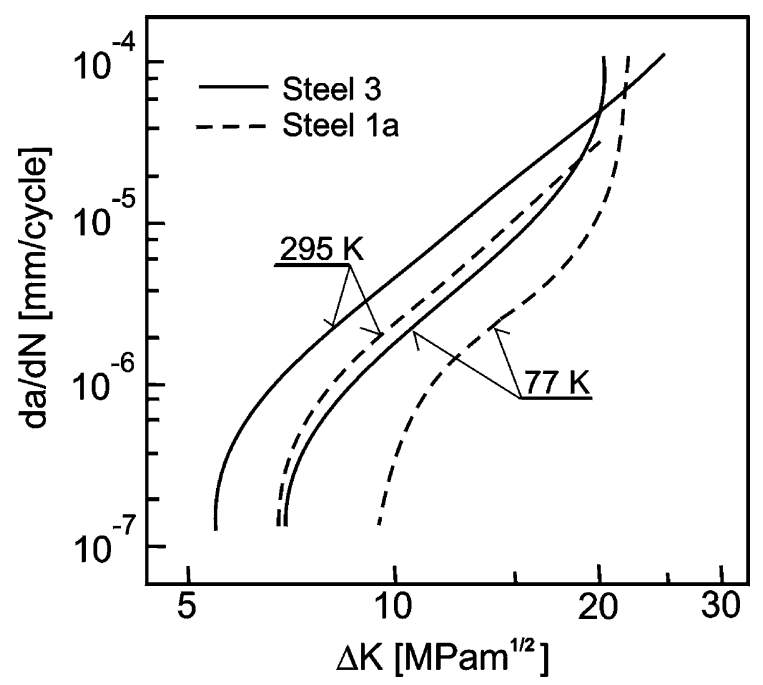

Fig. 6. Comparison of fatigue crack growth behaviour for steels with two extreme microstructures (steel 1a, $d_{\mathrm{f}}=88.4 \mu \mathrm{m}$ and steel $\left.3, d_{\mathrm{f}}=2.7 \mu \mathrm{m}\right)$.

curves is approximately parallel for the FCG rates $d a / d N<$ $10^{-5} \mathrm{~mm} /$ cycle and when compared to $T=295 \mathrm{~K}$ equal $\mathrm{FCG}$ rate can be observed at $77 \mathrm{~K}$ at $\Delta K$ values 1.25 to 1.5 times higher $\Delta K$ values.

The effect of the grain size on the FCG behavior is illustrated in Fig. 6, by means of the curves which represent the best-fit lines through the scatter-band data from Figs. 1 and 5. The comparison of the curves for these two extreme microstructures (steel $1 \mathrm{a}, d_{\mathrm{f}}=88.4 \mu \mathrm{m}$ and steel $3, d_{\mathrm{f}}=2.7 \mu \mathrm{m}$ ) shows that the steel which has a coarser grain size has likewise the larger resistance to the FCG rates over a broad range of $\Delta K$ levels except region III $\left(\approx d a / \mathrm{d} N>10^{-5}\right.$ $\mathrm{mm} /$ cycle). From the $d a / d N-\Delta K$ dependencies in Fig. 6 it is apparent that the influence of the temperature on the crack growth rates was greater in coarse grained microstructure. It is interesting to note that the FCG behavior of steel 1a at temperature of liquid nitrogen is comparable to steel 3 at room temperature.

From the comparison of the data of Table 1 it is clear that 


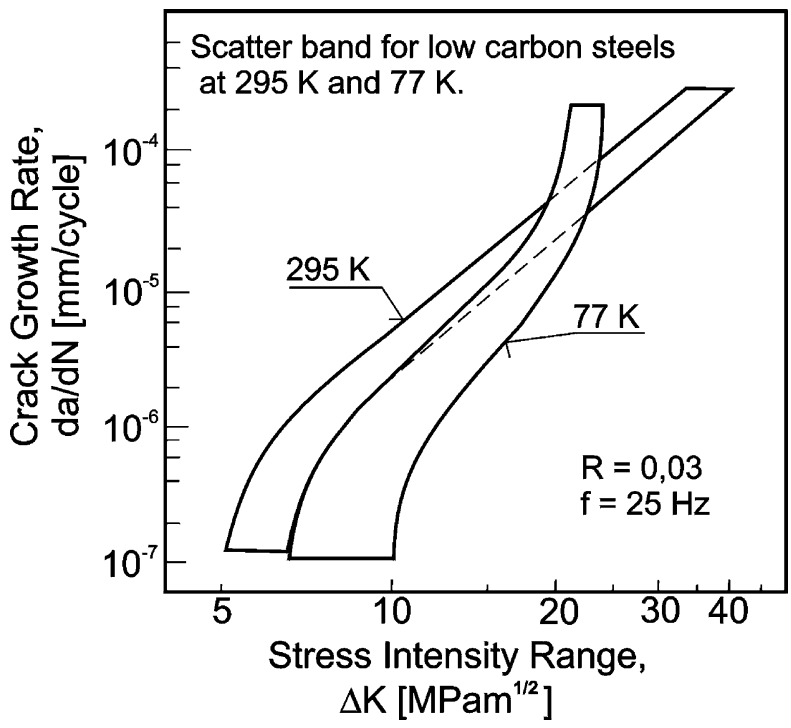

Fig. 7. Scatterband of fatigue crack growth behaviour in mild, low alloy and HSLA steels with low carbon contents.

grain size increase results also in the increase of the threshold values $\Delta K_{\mathrm{th} 295}$ and $\Delta K_{\mathrm{th} 77}$ and the order of the structural states made on the basis of their FCG resistance is the same for both of the temperatures. On the other hand, it can be seen that at the same temperatures only the coarse grain structures (steels 1a and 1b) exhibited clearly higher thresholds, in the case of the other three microstructures less significant differences were noted.

The influence of microstructure on crack growth rate at temperatures of $295 \mathrm{~K}$ and $77 \mathrm{~K}$ is summarized in Fig. 7. This figure shows the scatter bands which were constructed by combining the data from Figs. 1 to 5 and also include the results for further two mild steels, for five HSLA steels and for two low-alloyed steel in four different structural states. ${ }^{17)}$ From comparison of the scatter bands for both the temperatures in Fig. 7, it is clear that the difference in the FCG behavior of the various types of materials decreases as $\Delta K$ rises. These differences in comparison to Figs. 1-6 could be ascribed to the relatively higher scatter of the measured data in the threshold region but principally to the fact that at higher levels loading only small differences in the fatigue crack growth behavior occurred.

As shown in Figs. 1 to 7, at temperature $77 \mathrm{~K}$ the acceleration in the FCG rate, typically above $\Delta K=16$ to 20 $\mathrm{MPam}^{1 / 2}$, can be observed. After transition from region II to region III and when the value $\Delta K$ achieved the level of $K_{\text {IfC }}\left(K_{\text {IfC }}\right.$ : cyclic fracture toughness) non-stable crack propagation was observed.

Contrary to the unfavorable effect of finer grain on the threshold values $\Delta K_{\text {th } 77 \mathrm{~K}}, \Delta K_{\text {th } 295 \mathrm{~K}}$ their beneficial effect is expected on the fracture toughness values. The results did not confirm these expectations since exactly in the steel with the finest grains (steel 3) was measured the lowest resistance to fatigue crack growth in the investigated range while the cyclic value of fracture toughness was also the lowest. ${ }^{17)}$ The same was observed in the case of impact tests. ${ }^{18)}$ It is evident, that differences in the FCG behavior presented in this work cannot be directly referred only to the effect of grain size, because in the case HSLA steels it is necessary to consider also the influence of precipitate

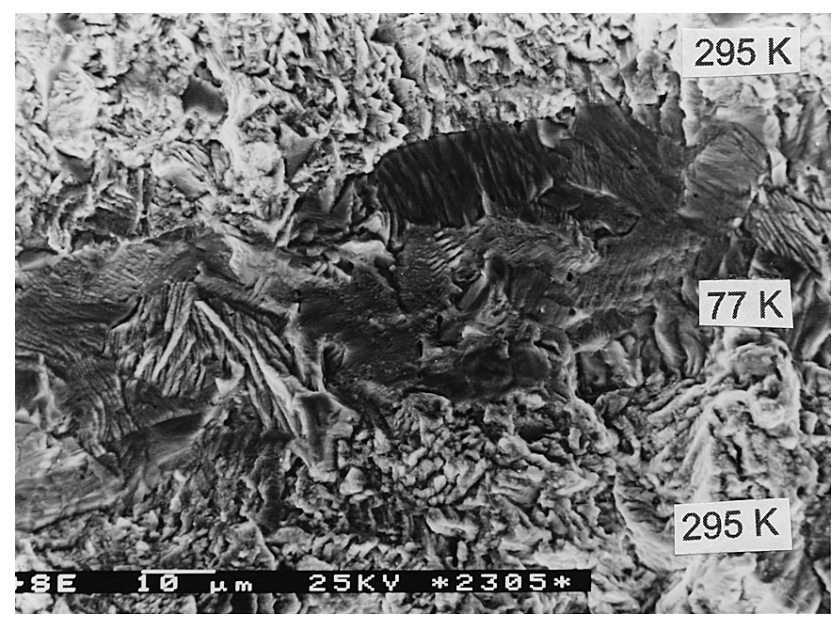

Fig. 8. Comparison of fracture surface roughness at 295 and $77 \mathrm{~K}$ for steels $2\left(d a / d N \approx 2 \times 10^{-7} \mathrm{~mm} /\right.$ cycle $)$. Crack growth from down to up.

characteristic (such as type, size, shape and distribution particles).

\subsection{Fractography}

The topographic features of fatigue fracture surfaces observed at room temperature with scanning electron microscopy are mostly in an agreement with the results of many investigators (for example, Refs. 10, 19, 20)). Crystallographic fracture facets and in restricted measure failure on the boundaries of grains in the near-threshold region for all structure states and ductile striations (except for steel 3) at the highest FCG rates were always visible.

The crystallographically dependent mechanism of crack growth was observed also at the temperature $77 \mathrm{~K}$. The damage mechanism for $d a / d N \leq 10^{-5} \mathrm{~mm} /$ cycle showed little dependence on $\Delta K$. The roughness of the fracture surface broken at $77 \mathrm{~K}$ was significantly lower than at the temperature 295 K (Fig. 8).

These results are consistent with the studies Liaw and Logsdon in Inconel 706 between $297 \mathrm{~K}$ and $4.2 \mathrm{~K}^{20)}$ Only at rates exceeding of the level $d a / d N=10^{-6} \mathrm{~mm} / \mathrm{cycle}$, the first isolated favorably oriented cleavage facets appear, limited by grain size. When the FCG rates are above $d a / d N=$ $10^{-5} \mathrm{~mm} /$ cycle also the appearance of brittle jumps especially in the fine grains steels was observed.

\section{Discussion}

It is clear that decreasing the temperature from 295 to $77 \mathrm{~K}$ the resistance to crack growth increases both in the threshold and Paris-regions. These results are predominantly qualitative in accordance with the findings of the references in Refs. 5)-14) and Refs. 20), 21). Yet, as mentioned in the introduction it is concluded, that a relationship should exist between the crack growth rate and the size of the cyclic plastic zone (CPZ) and CTOD.

(1) Threshold Condition for the FCG Based on a CPZ Criterion

In several papers it was considered that threshold occurs at that level of $\Delta K$ at which the $\mathrm{CPZ}$ in front of the crack tip is equal or smaller than the grain size $\left(d_{\mathrm{f}}\right)$. Taking into account the relation $\mathrm{CPZ} \approx d_{\mathrm{f}} \approx\left(\Delta K_{\mathrm{th}} / \sigma_{\mathrm{y}}\right)^{2}$, consequently, the 
existence of $\Delta K_{\mathrm{th}}-\sigma_{\mathrm{y}}$ correlation on the testing temperature can be presented also in the form ${ }^{21)}: \Delta K_{\text {th } 77 \mathrm{~K}} / \Delta K_{\text {th } 295 \mathrm{~K}}=$ $\sigma_{\mathrm{y} 77 \mathrm{~K}} / \sigma_{\mathrm{y} 295 \mathrm{~K}}$. Only in part are the results in Table 1 in accordance with this. With the increasing ratio $\sigma_{\mathrm{y} 77 \mathrm{~K}} / \sigma_{\mathrm{y} 295 \mathrm{~K}}$ also increases the ratio $\Delta K_{\text {th } 77 \mathrm{~K}} / \Delta K_{\mathrm{th} 295 \mathrm{~K}}$, and the highest value of $\Delta K_{\mathrm{th} 77 \mathrm{~K}}$ has the steel with coarse grains (steel 1a) which showed the highest yield stress increase between of 295 to $77 \mathrm{~K}$. On the other hand, the increase in thresholds is much less pronounced than the corresponding increase predicted from the above mentioned concept. In contrast to a 1.42 to 4.0 fold difference in the ratio of $\sigma_{\mathrm{y} 77 \mathrm{~K}} / \sigma_{\mathrm{y} 295 \mathrm{~K}}$, there was only a 1.21 to 1.37 fold difference in the ratio $\Delta K_{\text {th } 77 \mathrm{~K}} / \Delta K_{\text {th } 295 \mathrm{~K}}$ which was obtained between the two extreme structures (steel 1a and steel 3).

(2) Threshold Condition for the FCG Based on a CTOD Criterion

The relationship between $d a / d N$ and CTOD can be presented by the equation ${ }^{1)}$

$$
\frac{d a}{d N} \approx \mathrm{CTOD} \approx \frac{\Delta K_{\mathrm{th}}^{2}}{\sigma_{\mathrm{y}} \cdot E}
$$

where $E$ is the Young's modulus. If the threshold values $\Delta K_{\mathrm{th}}$ are correlated independently on the test temperature to the same critical values of $d a / d N$ and CTOD from the Eq. (1) the following relation can be written:

$$
\frac{\Delta K_{\text {th } 77 \mathrm{~K}}}{\Delta K_{\text {th } 295 \mathrm{~K}}}=\left(\frac{\sigma_{\mathrm{y} 77 \mathrm{~K}}}{\sigma_{\mathrm{y} 295 \mathrm{~K}}}\right)^{1 / 2} .
$$

For the formerly cited two extreme microstructural states the Eq. (2) supposes a ratio $\Delta K_{\text {th } 77 \mathrm{~K}} / \Delta K_{\text {th } 295 \mathrm{~K}}$ in the range from 1.19 (steel 3) to 2.0 (steel 1a), which are still significantly higher than the measured ones $\left(\Delta K_{\text {th } 77 \mathrm{~K}} / \Delta K_{\text {th } 295 \mathrm{~K}}=\right.$ 1.21 to 1.37). The reason for this discordance might be related primarily to the finding, ${ }^{2-4)}$ that the CPZ and CTOD parameters are more closely related to the cyclic yield stress, $\sigma_{\text {cy }}$, than the static yield stress, $\sigma_{\mathrm{y}}$. The values $\sigma_{\text {cy }}$ in the presented studies were not measured. However, as it showed in Ref. 22), $\sigma_{\text {cy }}$ values can be predicted by means of the ultimate tensile strength values, $\sigma_{\mathrm{u}}$. Tanaka et al. ${ }^{22)}$ on carbon steels and low alloy steels showed that independently on different cyclic deformation behavior of the steels for all cases the following relationship obtained: $\sigma_{\mathrm{yc}}=$ $0.608 \cdot \sigma_{\mathrm{u}}$ (where the cyclic yield stress, $\sigma_{\text {cy }}$, defined by the stress amplitude at plastic strain amplitude $\varepsilon_{\mathrm{ap}}=2 \times 10^{-3}$ ).

The dependence of threshold condition for the FCG of the $\sigma_{\mathrm{u}}$ assumed also Mc Clintock (cited in Ref. 10)). He hypothesized that crack growth at $\Delta K_{\mathrm{th}}$ might be controlled by the least possible crack tip displacement, one Burgers vector length or by a minimum plastic zone size which is assumed to be one dislocation spacing. Both approaches can be described by Eq. (3):

$$
\Delta K_{\mathrm{th}} \approx\left(E \cdot b \cdot \sigma_{\mathrm{u}}\right)^{1 / 2}
$$

where $E$ is the Young's modulus. As we can assume, the variations in $E \cdot b$, between 295 and $77 \mathrm{~K}$ are negligible, consequently, the temperature effect on the thresholds stress intensity values can be expressed, similarly to Eq. (2), in the form:
Table 2. Measured $\left(\Delta K_{\mathrm{th} 77 \mathrm{~K}}\right)$ and predicted $\left(\Delta K_{\mathrm{th} 77 \mathrm{~K}}^{*}\right)$ values of a thresholds stress intensity factors range at $77 \mathrm{~K}$.

\begin{tabular}{lrlllll}
\hline & & Steel 1a & Steel 1b & Steel 1 & Steel 2 & Steel 3 \\
\hline $\mathrm{d}_{\mathrm{f}}$ & $(\mu \mathrm{m})$ & 88.4 & 63.4 & 14.8 & 6.3 & 2.7 \\
$\Delta \mathrm{K}_{\text {th77K }}$ & $\left(\mathrm{MPam}^{1 / 2}\right)$ & 9.6 & 8.5 & 7.6 & 7.5 & 6.8 \\
$\Delta \mathrm{K}_{\text {th77K }}\left(\mathrm{MPam}^{1 / 2}\right)$ & 9.8 & 8.9 & 8.2 & 7.5 & 6.5 \\
\hline
\end{tabular}

$$
\frac{\Delta K_{\text {th } 77 \mathrm{~K}}}{\Delta K_{\text {th } 295 \mathrm{~K}}}=\left(\frac{\sigma_{\mathrm{u} 77 \mathrm{~K}}}{\sigma_{\mathrm{u} 295 \mathrm{~K}}}\right)^{1 / 2} .
$$

The values of $\Delta K_{\mathrm{th} 77 \mathrm{~K}}$ calculated by means of Eq. (4) together with the measured values given in the Table 2 , where an excellent agreement can be observed.

However, as it was stated formerly the measured threshold values $\Delta K_{\text {th }}$ could be influenced by the employed methodology. Besides that the intensity of the shielding effect of crack closure could be dependent also on the test temperature. From comparison of fractography results at 295 and $77 \mathrm{~K}$ it was revealed that the level of fracture surface roughness at $77 \mathrm{~K}$ is much lower and thus less effect of the crack closure can be expected than those at $297 \mathrm{~K}$. Consequently, the measured ratios $K_{\text {th } 77 \mathrm{~K}} / \Delta K_{\text {th } 295 \mathrm{~K}}$ seem to be primarily dependent on the values of the thresholds measured at room temperature. Further, the effect of plasticityinduced and oxide-induced closure, crack branching has to be considered as well as other factors such as crack-tip branching, secondary cracking and overall tortuous crack path. ${ }^{2-4,16)}$ The above mentioned indicates that it is necessary to carry out further experiments to verify the results presented in this study.

\section{Conclusions}

(1) Fatigue crack growth (FCG) rates decreased with changing the temperature from 297 to $77 \mathrm{~K}$ in all microstructures tested except for the rates in excess of the level $2 \times 10^{-5} \mathrm{~mm} /$ cycle.

(2) The order of the investigated microstructural states arranged on the basis of their fatigue crack growth resistance was equal for both the temperatures. The highest resistance to fatigue crack growth was found in coarse grained microstructures. The influence of temperature decrease is also the most significant in these materials.

(3) The ratio of the threshold values of $\Delta K$ at room temperature $\left(\Delta K_{\text {th } 295}\right)$ and at the temperature of liquid nitrogen $\left(\Delta K_{\text {th } 77}\right)$ in steel with grain sizes of 2.7 to $88.4 \mu \mathrm{m}$ were in the range of 1.21 to 1.43 .

(4) It is shown that the ratio $\Delta K_{\text {th } 77} / \Delta K_{\text {th } 295}$ is proportional to the second root of the ratio of the tensile strengths at both temperatures i.e. $\Delta K_{\mathrm{th} 77} / \Delta K_{\mathrm{th} 295}=\left(\sigma_{\mathrm{u} 277} / \sigma_{\mathrm{u} 295}\right)^{1 / 2}$, as is originally suggested by Mc Clintock. ${ }^{18)}$

\section{REFERENCES}

1) S. T. Rolfe and J. M. Barsom: Fracture and Fatigue Control in Structures, Applications of Fracture Mechanism, Prentice Hall Inc., New Jersey, (1977), 208.

2) K. J. Miller: Fatigue and Fracture Mechanics, ASTM STP, 1296 (1997), 267.

3) K. Tanaka and Y. Nakai: Fatigue Eng. Mater. Struct., 6 (1983), 315.

4) Y. Akiniwa, K. Tanaka and H. Kimura: Fatigue Fract. Eng. Mater. 
Struct., 24 (2001), 817.

5) L. H. Burck and J. Weertman: Metall. Trans. A, 7A (1976), 257.

6) P. K. Liaw and M. E. Fine: Metall. Trans. A, 12A (1981), 1927.

7) K. J. Park and C. S. Lee: Int. J. Fatigue, 19 (1997), 353.

8) S. Konosu, T. Kishiro, O. Ivano, Y. Nunoya, H. Nakajima and H. Tsuji: Int. J. Fatigue, 19 (1998), 139.

9) M. Hojo, S. Matsudo, B. Fiedler, T. Kawada, K. Moriya, S. Ochiai and H. Aoyama: Int. J. Fatigue, 24 (2002), 109.

10) E. Tschegg and S. Stanzl: Acta Metall., 29 (1981), 33.

11) K. Haberz, R. Pippan and H. P. Stüve: Proc. of the 10th Cong. on Material Testing, Vol. II, Scientific Society of Mechanical Engineers, Budapest, (1991), 484.

12) L. T. Summers, J. R. Miller and J. R. Heim: Adv. Cryo. Eng., 36 (1990), 769.

13) W. Yu, K. Esaklul and W. W. Gerberich: Metall. Trans., 15A (1984),
889.

14) F. R. Stonesifer: Eng. Fract. Mech., 10 (1978), 305.

15) G. Rosenberg: Metalurgia, 40 (2001), 13.

16) G. Rosenberg: Fatigue Fract. Eng. Mater. Struct., 21 (1998), 727.

17) G. Rosenberg: Proc. of the 7th National Conf. on Degradation of Properties of Constructional Materials Caused by Fatigue, Žilina-Rajecké Teplice, Slovakia, (2001), 13 (in Slovak).

18) G. Rosenberg: Met. Mater, 34 (1996), 201 (in Slovak).

19) Y. Nakai, K. Tanaka and T. Nakanishi: Eng. Fract. Mech., 15 (1981), 291.

20) P. K. Liaw and W. A. Logsdon: Acta Metall., 36 (1988), 1731.

21) H. J. Choi and L. H. Schwartz: Metall. Trans. A, 14A (1983), 1089.

22) K. Tanaka, S. Nishijimi, S. Matsuoka, T. Abe and F. Kouzu: Fatigue Eng. Mater. Struct., 4 (1981), 97. 